\title{
Three step primary liver cancer prevention program utilizing dynamic tumor marker combination assay in high-risk patients with chronic hepatitis
}

\begin{abstract}
Background: For the past 30 years, our efforts have focused on the primary prevention of cancer through the use of a tumor marker combination assay. 1 However, an understanding has been difficult to achieve owing to the expansion of organspecific medicine. Patients with hepatitis B (HBV) and C virus (HCV) infections have about a 10 -fold higher risk of liver cancer than individuals without viral hepatitis. We therefore focused on high-risk patients with viral hepatitis to study the effectiveness of a three-step liver cancer prevention program over the course of 10 years.

Methods: The risk of cancer was assessed on the basis of the results of a $\square$ dynamic tumor marker combination assay and conventional liver-function tests. The 406 subjects included 54 patients with chronic HBV hepatitis infection and 352 patients with chronic HCV hepatitis infection. Interventional studies of methods to predict and prevent the development of liver cancer were performed. The high risk subjects were treated with holistic methods that included dietary and life style change (dietary energy restriction) as well as a high dose of vitamin C, vitamin A, branched-chain amino acid granules and vitamin $\mathrm{K} 2$ as the first step. Intake of herbal medicine (Sun Advance) and detoxifying therapy constituted the second step, and local radiofrequency hyperthermia was the third step of liver cancer prevention program.

Results: In the 406 patients with chronic hepatitis, the response to treatment to prevent the development of liver cancer in this 10-year survey was as follows: improvement was obtained in all 136 patients with mild hepatic fibrosis (F1) and 144 patients with moderate hepatic fibrosis F2. Among the 49 patients with advanced fibrosis F3, 34 improved, but 15 did not show no improvement. Among the 77 patients with cirrhosis (F4), 44 patients improved, while 33 patients showed no signs of improvement. Our three-step primary liver cancer prevention program thus effectively prevented the development of liver cancer in $99 \%$ of high-risk patients with chronic hepatitis. Liver cancer developed in only 3 patients $(0.7 \%)$.
\end{abstract}

Conclusion: Our three-step liver cancer prevention program effectively prevented the development of liver cancer in high-risk patients with chronic hepatitis.

Keywords: liver cancer prevention program, high dose vitamin C, vitamin A intake, branched-chain amino acid granules, vitamin $\mathrm{K}$, herbal medicine (sun advance), detoxifying treatment
Volume I Issue 3 - 2018

\section{Tsuneo Kobayashi}

International cancer prevention center, Japan

Correspondence: Tsuneo Kobayashi, International cancer prevention center, Chiba city, 3-2I-I,Takasu, Mihamaku, Chiba city 26I-0004, Japan, Tel 043-306-26 I I, Fax 043-279-42 I I, Email ft1992@vega.ocn.ne.jp

Received: April 18, 2018 | Published: May 09, 2018

\section{Introduction}

The increased prevalence of hepatitis $\mathrm{C}$ virus $(\mathrm{HCV})$ infection has led to higher mortality rates from liver cancer in Japan. We have conducted a three-step primary cancer prevention program utilizing a dynamic tumor marker combination assay to comprehensively prevent all types of cancer in 21000 subjects over the course of 30 years. ${ }^{1}$ However, it has been difficult for Western physicians to understand systemic cancer prevention programs because Western medicine focuses on specific organ systems. On the other hand, hepatologists have reported that branched-amino acid granules inhibit liver carcinogenesis in patients with severe liver cirrhosis. ${ }^{2}$ We therefore focused on the prevention of liver cancer among patients with chronic hepatitis and patients with liver cirrhosis over a period of 10 years applying a three-step primary liver cancer prevention program utilizing a tumor marker combination assay and routine laboratory examination. Recently, Narumiya et al have shown that vitamin A-storing hepatic stellate cells clearly participate in hepatocytes fibrosis in a mouse model of immune-mediated hepatitis. ${ }^{3}$ We have long studied the relations of vitamin A concentrations to immunity and liver fibrosis. The degree of fibrosis was classified from $F_{0}$ to $F_{4}$ according to the criteria proposed by Japan Society of Hepatology.

The vitamin A serum concentration, white blood cell (WBC) count, $\mathrm{T}$ cell count, and natural killer (NK) cell activity at initial presentation were measured in 44 patients with chronic hepatitis, among whom $40 \%$ had HBV hepatitis and 60\% had HCV hepatitis (Table 1). Patients with mild hepatitis with no progression of fibrosis were classified as $\mathrm{F}_{0}$. As hepatitis-related fibrotic changes progressed from $\mathrm{F}_{1}$ to $\mathrm{F}_{4}$, the vitamin A serum concentration, WBC count, T-cell count, and natural killer (NK) cell activity progressively decreased (Table 1). On the basis of these data, we established a global strategy for treatment. Patients with liver cancer, immuno suppression, or chronic inflammation were given high-dose vitamin C therapy. Patients with fibrosis received vitamin A supplementation, and patients with evidence of liver cancer cells received herbal medicine (Sun Advance), 
branched-chain amino acid granules, and vitamin $\mathrm{K}_{2}$ (Glakay) Patients with immuno suppression were given detoxification therapy as part of this comprehensive treatment strategy. If evidence of liver cancer was detected, local radio-frequency was performed. Vitamin A

Table I Degree of hepatic fibrosis risk classification

\begin{tabular}{llllll}
\hline & $\mathbf{F}_{0}$ & $\mathbf{F}_{1}$ & $\mathbf{F}_{2}$ & $\mathbf{F}_{3}$ & $\mathbf{F}_{4}$ \\
\hline Vitamin A & $65.5( \pm 16.5) \square$ & $44.8 \pm 40.5 \square$ & $32( \pm 5 I)$ & $28.7( \pm 3.6)$ & $16.8( \pm 34)$ \\
WBC & $5950 \pm 1970$ & $4740( \pm 900)$ & $3807( \pm 2900)$ & $3994( \pm 1300)$ & \\
T cell $\square$ & $1837( \pm 60)$ & $1449( \pm 184)$ & $908( \pm 130)$ & $700( \pm 260)$ & \\
Stimulation Index $(\mathbf{S I})$ & $230( \pm 39)$ & $137( \pm 85)$ & $190( \pm 59)$ & $184( \pm 116)$ & \\
NK cell & $34( \pm 15)$ & $33( \pm 14)$ & $27( \pm 8)$ & $26( \pm 10)$ & \\
\hline
\end{tabular}

Vitamin A was determined by Thompson et al. ${ }^{4}$ method. ${ }^{4}$

Immune activity was measured by the method of Hoffman RA et al. ${ }^{5}$

Examination data are obtained from 44 viral chronic hepatitis patients.

\section{Subjects and materials}

The study group comprised a total of 406 patients, including 54 patients with chronic HBV hepatitis infection and 352 patients with chronic HCV hepatitis infection. Seventy-seven patients had liver cirrhosis $\left(\mathrm{F}_{4}\right)$. Their ages ranged from 24 to 72 years. The degree of fibrosis was classified from $\mathrm{F}_{0}$ to $\mathrm{F}_{4}$ according to the criteria proposed by the Japan Society of Hepatology, which are based on the platelet count, hyaluronic acid concentration, type IV collagen concentration, and cholinesterase activity. In the patients with HBV hepatitis, fibrosis was $F_{1}$ in 10 patients, $F_{2}$ in 16 patients, $F_{3}$ in 19 patients, and $F_{4}$ in 9 patients. In the patients with HCV hepatitis, fibrosis was $F_{1}$ in 126 patients, $F_{2}$ in 128 patients, $F_{3}$ in 30 patients, and $F_{4}$ in 68 patients. Evaluation criteria were based on the improvement of the following liver function data (GOT, GPT, choline esterase, total bile acid, adenosine deaminases (ADA), platelet number, albumin, $\gamma$-globulin and $\gamma$ - glutamyl transpeptidase ( $\gamma$-GTP) The criteria of conventional liver function tests are as follows.: platelet $\mathrm{F}_{1}\left(18 \times 10^{4} / 1 \mathrm{~mm}^{3}>\right), \mathrm{F}_{2}$ $\left(15 \times 10^{4} / 1 \mathrm{~mm}^{3}>\right), \mathrm{F}_{3}\left(13 \times 10^{4} / 1 \mathrm{~mm}^{3}>\right)$ and $\mathrm{F}_{4}\left(10 \times 10^{4} / 1 \mathrm{~mm}^{3}>\right)$ and hyaluronic acid $\left(\mathrm{F}_{1}, \mathrm{~F}_{2}\right.$ : under $50 \mathrm{ng} / \mathrm{ml}, \mathrm{F}_{3}: 50-80 \mathrm{ng} / \mathrm{ml}$ and $\mathrm{F}_{4}$ : over $80 \mathrm{ng} / \mathrm{ml})$ and 4 type of collagen $\left(\mathrm{F}_{1}, \mathrm{~F}_{2}\right.$ : under $150 \mathrm{ng} / \mathrm{ml}, \mathrm{F}_{3}: 150$ $200 \mathrm{ng} / \mathrm{ml}$ and $\mathrm{F}_{4}$ : over $\left.200 \mathrm{ng} / \mathrm{ml}\right)$ and choline esterase value $\left(\mathrm{F}_{1}\right.$, $\mathrm{F}_{2}$ :under $230 \mathrm{U} / \mathrm{L}, \mathrm{F}_{3}: 230-150 / \mathrm{L}$ and $\mathrm{F}_{4}$ : under $\left.150 \mathrm{U} / \mathrm{L}\right)$. In the patients with $\mathrm{HBV}$ hepatitis, fibrosis was $\mathrm{F}_{1}$ in 10 patients, $\mathrm{F}_{2}$ in 16 patients, $\mathrm{F} 3$ in 19 patients, and $\mathrm{F}_{4}$ in 9 patients. In the patients with $\mathrm{HCV}$ hepatitis, fibrosis was $F_{1}$ in 126 patients, $F_{2}$ in 128 patients, $F_{3}$ in 30 patients, and $\mathrm{F}_{4}$ in 68 patients.

Our liver primary cancer prevention program consisted of three steps.

1. First step: The patients were recommended to stop smoking, stop drinking alcoholic beverages, avoid over work, increase their intake of green and yellow vegetables, take a high dose $(>6 \mathrm{~g})$ of vitamin $\mathrm{C}$ daily, ${ }^{6,7}$ and to take three $20 \mathrm{mg}$ tablets of retinol palmitate (Chocola A) daily until their serum vitamin A level reached $700 \mu \mathrm{g} /$ dL. ${ }^{8-10}$ Branched-chain amino acid granules $(12 \mathrm{~g} / \text { day })^{2}$ and vitamin $\mathrm{K}_{2}$ ( Glakay $45 \mathrm{mg} /$ day $)^{11}$ were also recommended.

2. Second step: If the first step was not effective, the patients were given intravenous infusions of high dose of vitamin C (20-30g) one or two times per week. ${ }^{6,7}$ Detoxification therapy was given was measured using the methods of Thompson et al. ${ }^{4}$ Immune activity was measured using the method of Hoffman RA et al. ${ }^{5}$

Examination data were obtained from 44 viral chronic hepatitis patients. one to three times per week. As shown in Figure 1, the one to two high doses of vitamin $\mathrm{C}$ per week were effective in nearly all patients. Patients who did not respond to these treatments were given herbal medicine (Sun Advance, 1.6 gram per day, Chiba City IMHC Clinic, which inhibits aerobic respiration of cancer cells. ${ }^{12-14}$ Detoxification therapy was performed by the Nishi health therapy technique, using a Nishi-type device (Orthopedic Traction Apparatus, WA 57B (686) Yamato KK, Ehime Prefecture, Japan). Exercise therapy was performed for 20 to 30 minutes). To cleanse the colon, the patients orally ingested a detoxification preparation consisting of citric acid (12g) lactulose ( $24 \mathrm{~g}$, Kowa, Tokyo, Japan), and magnesium hydroxide $(30 \mathrm{~g})$ dissolved in $50 \mathrm{ml}$ of water.

3. Third step: If no improvement was observed, radio-frequency treatment (local hyperthermia) ${ }^{15-18}$ was recommended.

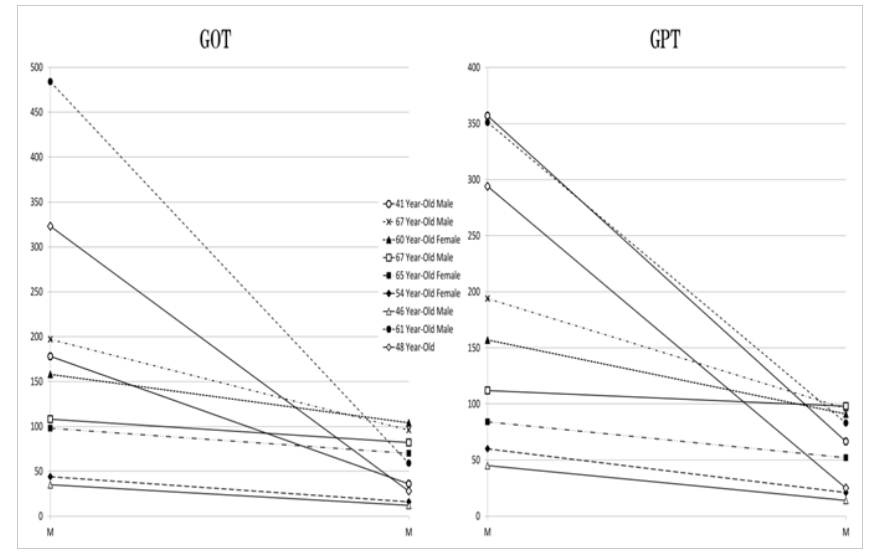

Figure I Shows the effects of high-dose vitamin $C$ on aspartate transaminase (GOT). And alanine transaminase (GPT) in chronic viral hepatitis patients GOT and GTP values before and after high-doses of vitamin C (20-30grams) treatment I or 2times per week (total of I0times), or every day for I0days in severe cases.

\section{Preliminary results}

These data were obtained before and after high dose vitamin C (20-30 per application) treatment (Figure 1). These high-dose vitamin $\mathrm{C}$ treatments were performed, 1 or 2 times per week (for a total of 10times) or for severe cases, every day of for 10days. The results 
show the effects of high dose vitamin $\mathrm{C}$ treatment on GOT and GPT even if the interferon treatment was not effective. We describe a 41 year-old man with HBV hepatitis. The serum Glutamic Oxaloacetic Transaminase activity (GOT) and Glutamic Pyruvic Transaminase activity (GPT) were in the range of 300 to 400 , and received interferon in a large hospital for 2 years, but there was no improvement. He presented at our hospital in September 1994 and intravenously received 14 high doses $(20 \mathrm{~g})$ of vitamin C therapy. After 2 months, his data were within the normal range. There has been no exacerbation for 6 years. High-dose vitamin $C$ therapy was very effective for suppressing live inflammation and inhibiting the development of cancer cells (Table 2). High-dose vitamin C (20-30g per dose) was consistently effective for treating hepatitis except for patients who had fulminant hepatitis or autoimmune hepatitis. Patients with fulminant hepatitis required 24-hour intravenous infusion of about $120 \mathrm{~g}$ of vitamin C. In patients who received detoxification therapy, the effectiveness was evaluated by measuring the following substances after every 3 sessions of treatment: carcinoembryonic antigen (CEA) as an immunosuppressive substance, ferritin as serum protein that stores and release iron, $\alpha 1$-globulin, and $\alpha 2$-globulin levels decreased. The immune activity improved after three sessions of detoxification therapy. In addition, the T-cell count increased from 1,252 to 2,184. Detoxification therapy thus enhances immune activity, contributing to the suppression of carcinogenesis in patients with chronic hepatitis. Result of Table 3 provides data for the application of detoxification therapy in a 57 -year-old female. $\square$

Table 2 This patient was $4 \mathrm{I}$-year-old male suffering from $\mathrm{HBV}$ infection. The patient was treated with interferon for 2 years with no effect. He arrived at the hospital in September, 1994 and received high-dose vitamin C treatment for 2 Idays. After 2 months, his data was within the normal range

\begin{tabular}{lllllll}
\hline & 28-Sep & II-Oct & 22-Oct & I4-Nov & 27-Dec & 24-Feb \\
\hline GOT & 294 & 247 & 187 & 26 & 18 & 25 \\
GPT & 323 & 269 & 213 & 25 & 12 & 5 \\
\hline
\end{tabular}

Table 3 Detoxification treatment for on a 57-year-old female

\begin{tabular}{llll}
\hline Detoxifying therapy: & 3 times & 3 times & \\
\hline Date: I983 & $5 / 9$ & 2-Jun & $11 / 4$ \\
CEA $(\mathrm{ng} / \mathrm{ml})$ & 3.1 & 2.1 & 1.4 \\
Ferritin $(\mathrm{ng} / \mathrm{ml})$ & 203 & 85 & 60 \\
$\alpha$ I-globulin (\%) & 5.7 & 3 & \\
$\alpha 2-$ globulin $(\%)$ & 11.9 & 8.3 & \\
T (\%) & 73 & 78 & 78 \\
T cell number & 1252 & 1460 & 2184 \\
Stimulation index & 165 & 202 & 152 \\
\hline
\end{tabular}

The data were measured after every 3time's application of detoxification therapy.

According to the decreasing level of immunosuppressive substances (CEA, ferritin, $\alpha$-immuno-regulatory protein), the immune activity ranged from I, 252 to 2,184 .

\section{Results}

The results of 10 year intervention studies using this global strategy to prevent the development of liver cancer in 406 patients are shown in Table 4. After 10 years, improvement was obtained in 136 patients with $\mathrm{F}_{1}$ fibrosis and 144 patients with $\mathrm{F}_{2}$ fibrosis. Among the 49 patients with $\mathrm{F}_{3}$ fibrosis, improvement was obtained in 34 patients, and 15 patients were unchanged. Among the 77 patients with $\mathrm{F}_{4}$ fibrosis, 44 patients improved, and 33 patients were unchanged. Over the past ten years, three patients suffered from hepatoma. Thus, liver cancer suffering rate was $0.7 \%(3 / 406)$ (Table 4$)$.

Table 4 Platelet number is classified by fibrotic degree as follows:

\begin{tabular}{lllll}
\hline Prognosis & Pt number & $\begin{array}{l}\text { better } \\
\text { change }\end{array}$ & $\begin{array}{l}\text { no } \\
\text { change }\end{array}$ & aggravation \\
\hline $\begin{array}{l}\text { Chronic } \\
\text { hepatitis } \\
\text { classification }\end{array}$ & & & & \\
$\mathbf{F}_{1}$ & 136 & 136 & & \\
$\mathbf{F}_{2}$ & 144 & 144 & & \\
$\mathbf{F}_{3}$ & 49 & 34 & 15 & 3 \\
$\mathbf{F}_{4}$ & 77 & 44 & 33 & 3 \\
\hline
\end{tabular}

$F_{1}: 18 \times 10^{4} / I \mathrm{~mm}^{3}>, F_{2}: 15 \times 10^{4} / \mathrm{Imm}^{3}>, F_{3}: 13 \times 10^{4} / 1 \mathrm{~mm}^{3}>, F_{4}: 10 \times 10^{4} / \mathrm{Imm}^{3}>$

\section{Discussion}

Fibrosis in patients with chronic viral hepatitis is associated with decreased vitamin A levels in serum. Patients thus require vitamin A supplementation. Patients with liver fibrosis should also receive branched-chain amino acid granules and vitamin $\mathrm{K}$. In patients with immuno suppression, detoxification therapy as part of the global treatment strategy is thought to have inhibited the exacerbation of chronic hepatitis and the development of liver cancer. Although improvement was not obtained in all patients, we believe that our results showed that three sessions of proactive prophylactic therapy were an effective intervention. Recently, Kanto et al. ${ }^{19}$ reported that immune therapy by the transfusion of dendritic cells prevents the development of liver cancer, indicating that the prevention of immuno suppression is important. Because chronic hepatitis is a type of latent infection, ${ }^{20}$ cold beverage consumption and mouth breathing must be avoided. Moreover, even if $\mathrm{HBe}$ antibodies become positive, the process of hepatitis continues, and interferon is often ineffective. In Japan, about $70 \%$ of viral hepatitis cases by HCV, and a high proportion of $\mathrm{HCV}$ infections are genotype 1b. Interferon is thus often ineffective. ${ }^{21-25}$ In the present study, we did not use interferon or oligo nucleotide preparations. Basically, $85 \%$ to $90 \%$ of hepatic viral infections are spontaneously cured by sero conversion. It is therefore, important to develop methods for enhancing immunity and thereby prevent the development of liver cancer.

\section{Acknowledgements}

I am grateful to my co-worker: Hayashida Shigeru and Takeda Yoshio.

\section{Conflict of interest}

Author declares that there is no conflict of interest.

\section{References}

1. Kobayashi T, Kawakubo T. Prospective investigation of tumor markers and risk assessment in early Cancer screening. Cancer. 1994;73(7):1946-1953. 
2. Muto Yasutoshi, Sato Shunichi, Watanabe Akiharu, et al. Overweight and obesity increase the risk for liver cancer in patients with liver cirrhosis and long-term oral supplementation with branched-chain amino acid granules inhibits liver carcinogenesis in heavier patients with liver cirrhosis. Hepatol Res. 2006;35(4):204-214.

3. Tomoko Fujita, Kitipong Soonntrapa, Yoshiya Ito, et al. Hepatic stellate cells relay inflammation signaling from sinusoids to parenchyma in mouse models of immune-mediated hepatitis. Hepatology. 2015;63(4):1325-1339.

4. Thompson JN, Erdody P, Brien R, et al. Fluorometric determination of vitamin A in human blood and liver. Biochem Med. 1971;5(1):67-89.

5. Hoffman RA, Kung PC, Hansen WP, et al. Simple and rapid measurement of human T lymphocytes and their subclasses in peripheral blood. Proc Natl Acad Sci USA. 1980;77(8):4914-7.

6. Chen Qi, Espey MG, Krishima MC, et al. Pharmacologic ascorbic acid concentrations selectively kill cancer cells Action as pro-drug to deliver hydrogen peroxide to tissues. Proc Natl Acad Sci U S A. 2005;102( 38):13604-13609.

7. Chen Q, Espey MG, Sun AY, et al. Ascorbate in pharmacologic concentrations selectively generates ascorbate radical and hydrogen peroxide in extracellular fluid in vivo. Proc Natl Acad Sci U S A. 2007;104(21):8749-8754.

8. Smith JE, Muto Y, Milch PO, et al. The effects of chylomicron Vitamin A on the Metabolism of Retinol binding protein in the Rat. J Biol Chem. 1973;248(5):1544-1549.

9. Muto Y, Moriwaki M, Ninomiya S, et al. Prevention of second primary tumors by an acyclic retinoid. Polyprenoic acid in patients with hepatocellular carcinoma. $N$ Engl J Med. 1996;334(24):1561-1567.

10. Muto Y, Smith JE, Milch PO, et al. Regulation of retinol-binding protein Metabolism by vitamin A status in the Rat. J Biol Chem. 1972;247(8):2542-2550.

11. Koike Y, Shiratori Y, Shiina S et al. Randomized prospective study of prevention from tumor invasion into portal vein in 120 patients with hepatocellular carcinoma by vitamin K2 administration. Gastroenterology. 2002;122:643a.

12. Kobayashi T, Tanimizu T, et al. 32 Proceeding of J Cell Biology. 1979;87.

13. Sugimoto $\mathrm{K}$, Jo T, Tanimizu T, et al. The effect of the anti-tumor herb medicine" Sun Advance" in mice. Proc Symposium WAKAN-YAKU. 1982;15:224-227.
14. Tanimizu T, Sugimoto K, Hayashi N, et al. New approach to Chinese herb medicine, inhibition by Chinese herb medicine" Sun Advance" of SV40 transformation in mouse cells. Proc Symposium WAKAN-YAKU. 1982;15:228-233x.

15. Udono H. Srivastava PK. Comparison of tumor specific immunogenetics of stress induced protein gp96, HSP90 and hsp70. J Immunol. 1994;152(11):5398-5403.

16. Yoko I, Tazawa K, Wada S, et al. Induction of HSP70 in lymphocytes by whole body hyperthermia Far-infrared Hyperthermia. Japanese $J$ Hyperthermic Oncol. 2005;21(4);209-220.

17. Hayashida S, Sugimoto K, Kobayashi T. The clinical effect of hyperthermia combined with induced hypertension chemotherapy. Gan To Kagaku Ryoho. 1984;11(6):1218-1224.

18. Hayashida S. Sugimoto K, Kobayashi T. Effect of BRM-induced systemic hyperthermia combined with Immunochemotherapy on advanced breast cancer metastasis. $5^{\text {th }}$ International Symposium on Hyperthermic Onology. $1987 ; 361$

19. Kanto T, Inoue M, Miyatake H. et al. Reduced numbers and impaired ability of myeloid and plasmacytoid dendritic cells to polarize T helper cells in chronic hepatitis C virus infection. J Infect Dis. 2004;190(11):1919-1926.

20. Majid Ali. Oxidative regression to primodal cellular ecology. Journal of Integrative Medicine. 1998;2:4-55.

21. Chen CJ, Yang HI, Su J, et al. Risk of hepatocellular carcinoma across a biological gradient of serum hepatitis B virus DNA level. JAMA. 2006;295(1):65-73

22. Lok AS, Liang RH, Chiu EK et al. Reactivation of hepatitis B virus replication in patients receiving cytotoxic therapy. Report of a prospective study. Gastroenterology. 1991;100(1):182-188.

23. Enomoto M, Tamori A, Nishiguchi S et al. Combination therapy with a nucleoside analogue and interferon for chronic hepatitis B: simultaneous or sequential. J Gastroenterol. 2013;48(9):999-1005.

24. Tanaka J, Koyama T, Mizui M et al. Total number of undiagnosed carriers of hepatitis C and B viruses in Japan estimated by age- and area-specific prevalence on the national scale. Intervirology. 2011;54(4):185-195.

25. Ikeda K, Saitoh S, Kobayashi M et al. Distinction between chronic hepatitis and liver cirrhosis in patients with hepatitis $\mathrm{C}$ virus infection Practical discriminant using common laboratory data. Hepatol Res. 2000;18(3):252-266. 